\title{
BIOLOGICAL AND BACTERICIDAL PROPERTIES OF AG-DOPED BIOACTIVE GLASS IN A NATURAL EXTRACELLULAR MATRIX HYDROGEL WITH POTENTIAL APPLICATION IN DENTISTRY
}

\author{
Y-Y. Wang ${ }^{1,2, *}$, X. Chatzistavrou, ${ }^{1, *}$, D. Faulk ${ }^{3}$, S. Badylak ${ }^{3,4,5}$, L. Zheng ${ }^{1}$, S. Papagerakis ${ }^{6,7}$, L. Ge ${ }^{2}$, H. Liu ${ }^{2, \S}$ and P. Papagerakis ${ }^{1,8,9, \S, *}$ \\ ${ }^{a}$ Department of Orthodontics and Pediatric Dentistry, School of Dentistry, University of Michigan, Ann Arbor, MI, USA \\ ${ }^{b}$ Department of Pediatric Dentistry, School \& Hospital of Stomatology, Peking University, Beijing, China \\ ${ }^{\mathrm{c}}$ McGowan Institute for Regenerative Medicine, University of Pittsburgh \\ ${ }^{\mathrm{d}}$ Department of Surgery, University of Pittsburgh \\ ${ }^{\mathrm{e}}$ Department of Bioengineering, University of Pittsburgh \\ ${ }_{\mathrm{f}}^{\mathrm{f}}$ Department of Otolaryngology, Medical School, University of Michigan, Ann Arbor, MI, USA \\ ${ }^{g}$ Department of Periodontics \& Oral Medicine, School of Dentistry, University of Michigan, Ann Arbor, MI, USA \\ ${ }^{\mathrm{h}}$ Center for Organogenesis, Medical School, University of Michigan, Ann Arbor, MI, USA \\ ${ }^{\mathrm{i}}$ Center for Computational Medicine \& Bioinformatics, Medical School, University of Michigan, Ann Arbor, MI, USA \\ "These authors contribute equally as first authors.

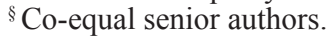

\begin{abstract}
The aim of this study was the fabrication and evaluation of a novel bioactive and bactericidal material, which could have applications in dentistry by supporting tissue regeneration and killing oral bacteria. Our hypothesis was that a new scaffold for pulp-dentin tissue engineering with enhanced antibacterial activity could be obtained by associating extracellular matrix derived from porcine bladder with an antibacterial bioactive glass. Our study combines in vitro approaches and ectopic implantation in scid mice. The novel material was fabricated by incorporating a sol-gel derived silver (Ag)-doped bioactive glass (BG) in a natural extracellular matrix (ECM) hydrogel in ratio $1: 1$ in weight $\%(\mathrm{Ag}-\mathrm{BG} / \mathrm{ECM})$. The biological properties of the $\mathrm{Ag}-\mathrm{BG} / \mathrm{ECM}$ were evaluated in culture with dental pulp stem cells (DPSCs). In particular, cell proliferation, cell apoptosis, stem cells markers profile, and cell differentiation potential were studied. Furthermore, the antibacterial activity against Streptococcus mutans and Lactobacillus casei was measured. Moreover, the capability of the material to enhance pulp/dentin regeneration in vivo was also evaluated. Our data show that Ag-BG/ECM significantly enhances DPSCs' proliferation, it does not affect cell morphology and stem cells markers profile, protects cells from apoptosis, and enhances in vitro cell differentiation and mineralisation potential as well as in vivo dentin formation. Furthermore, Ag-BG/ECM strongly inhibits $S$. mutans and $L$. casei growth suggesting that the new material has also anti-bacterial properties. This study provides foundation for future clinical applications in dentistry. It could potentially advance the currently available options of dental regenerative materials.
\end{abstract}

Keywords: Ag-doped bioactive glass, natural extracellular matrix hydrogel, dental pulp stem cells, biological properties, antibacterial activity.

*Address for correspondence:

Petros Papagerakis, DDS, MS, PhD

School of Dentistry, 1011 North University

Ann Arbor, MI, 48109, USA

Telephone number: +1 2108459190

E-mail: petrosp@umich.edu

\section{Introduction}

It has been observed that two-thirds of all restorative dentistry involves the replacement of failed restorations (Maupomé and Sheiham, 1998; Burke et al., 1999). The development of innovative bactericidal, bioactive/ biomimetic ion-releasing restorative materials that could heal and regenerate the defect area, consists one of the main targets in dental biomaterials research (Sauro et al., 2013).

Regarding pulp-dentin regeneration, several types of scaffolds have been tested combined with dental pulp stem cells (DPSCs) both in vitro and in vivo (Demarco et al., 2010; Wang et al., 2010; Galler et al., 2012). However, all those studies regenerated only a limited number of dental tissues, while none of them has been used in clinical trials. The challenge to develop a suitable scaffold that can provide a suitable microenvironment for DPSC proliferation, differentiation and new tissue formation still remains.

Towards this aim, natural extracellular matrix (ECM) scaffolds are considered advantageous because of their inherent bioactive properties and ability to mimic the native microenvironment niche (Currie et al., 2001; Patino et al., 2002). ECM hydrogels have been successfully isolated and used in several regenerative medicine applications (Turner et al., 2010; Valentin et al., 2010; Singelyn et al., 2012). ECMs have been shown to promote tissue healing and regeneration in a number of anatomic locations, including skeletal muscle (Marelli et al., 2010; Mase et al., 2010), oesophagus (Nieponice et al., 2009) and urinary bladder (Boruch et al., 2010). However, it is not clear if they can inhibit pathogenic bacterial growth and prevent secondary caries formation (Ljungh et al., 1996). Moreover, natural ECM scaffolds have not been tested in detail for dental applications.

Bioactive glasses (BGs) are considered to be osteoconductive and osteoinductive, regulating genetic profiles of osteoprogenitor/stem cells down to the lineage of bone forming cells (Rezwan et al., 2006). Bioactive glasses are extensively used for bone reconstitution and tissue engineering (Blaker et al., 2003; Cushing et al., 2004), while they are also significant candidates for the remineralisation of tooth tissues (Forsback et al., 2004). However, BGs have not been shown to promote stem cell migration, as do ECM scaffolds. Moreover, BGs delivery needs to be facilitated by appropriate scaffold matrices. 
Therefore, the idea of using natural extracellular matrix hydrogels (ECMs) in concert with bioactive glasses is considered to be a promising strategy to attain cell matrices with physic-chemical and biological properties appropriate for tissue engineering.

On the other hand, several antimicrobial agents have been incorporated into dental restorative materials and bonding systems (Imazato et al., 2003) to prevent secondary caries. However, there is no definitive evidence that these antibacterial agents are effective in improving clinical outcomes (Pereira-Cenci et al., 2009). The antimicrobial use of silver $(\mathrm{Ag})$ compounds tends to be restricted to the extensive application of silver nitrate, silver foil, and silver sutures for the prevention and treatment of ocular, surgical, and dental infections. It has been observed that silver interacts with sulphydryl groups of proteins and with DNA, altering hydrogen bonding and inhibiting respiratory processes, DNA unwinding, cell-wall synthesis, and cell division (Oppermann et al., 1980; Lansdown, 2002; 2006). These interactions critically effect bacterial killing and inhibit biofilm formation at the macro level ( $\mathrm{Wu}$ et al., 2007). The interaction of silver with thiol groups is considered to be the central mechanism of these diverse effects (Russell et al., 1994).

We have recently fabricated a new sol-gel derived silver-doped silicate glass (Ag-BG) that presents strong anti-bacterial and bioactive properties (Chatzistavrou et al., 2014). Ag-BG can effectively inhibit bacteria growth, by the ion release process of $\mathrm{Ag}$. Moreover, the composition of Ag-BG presents $\mathrm{Ca} / \mathrm{P}$ ratio around 4 which can enhance the deposition of apatite phase (Chatzistavrou et al., 2012). This remineralisation process can be described as a slow dissolution/precipitation process of mineral constituents into the dentin matrix. Apatite could subsequently develop a strong bond with the surrounding tooth tissue, eliminating the possibility of future micro-penetrations. Similar compositions have been already used for bone repair applications, both at the experimental and clinical levels (Kellomaki et al., 2000). In dentistry, silver containing bioactive glass with different composition has been also reported (Balamurugan et al., 2008); however, the proposed injectable combination of Ag-BG with ECM has not been adopted before.

Many studies have also revealed that silicate bioactive glasses stimulate the growth and osteogenic differentiation of human primary osteoblasts (Xynos et al., 2000; Hench et al., 2004; Rahaman et al., 2011). However, to date, the effect of a silver doped silicate bioactive glass on human DPSCs is unclear. We hypothesise that the release of soluble silicon ions $\left(\mathrm{Si}^{4+}\right)$ from the degradation of $\mathrm{Ag}$ BG will contribute leading to favourable intracellular and extracellular responses promoting odontogenic differentiation of DPSCs.

The aim of this work is to generate and characterise a novel complex system (Ag-BG/ECM), fabricated through the incorporation of Ag-BG into natural ECM hydrogel. Our research hypothesis is that ECM facilitates the delivery of Ag-BG, making it injectable and potentially provides niche-like signals to DPSC. This work suggests that Ag$\mathrm{BG} / \mathrm{ECM}$ is able to stimulate and accelerate human DPSCs growth, differentiation potential and enhanced dentin formation in vivo, while also providing strong bactericidal properties against $S$. mutans and L. casei.

\section{Materials and Methods}

\section{Sample preparation \\ $A g-B G$}

The fabrication of the Ag-BG in the systems $\mathrm{SiO}_{2}$ 58.6$\mathrm{CaO} 24.9-\mathrm{P}_{2} \mathrm{O}_{5}$ 7.2- $-\mathrm{Al}_{2} \mathrm{O}_{3} 4.2-\mathrm{Na}_{2} \mathrm{O} \quad 1.5-\mathrm{K}_{2} \mathrm{O} \quad 1.5-\mathrm{Ag}_{2} \mathrm{O}$ 2.1 wt. \%, has been already described (Chatzistavrou et al., 2012). Briefly, the fabrication protocol is based on the sol-gel process by mixing the solution stage of the $58 \mathrm{~S}$ sol-gel bioactive glass (in the system $\mathrm{SiO}_{2} 58-\mathrm{CaO}$ $33-\mathrm{P}_{2} \mathrm{O}_{5} 9$ wt.\%), with the respective solution stage of the sol-gel glass in the system $\mathrm{SiO}_{2} 60-\mathrm{CaO} 6-\mathrm{P}_{2} \mathrm{O}_{5} 3-\mathrm{Al}_{2} \mathrm{O}_{3}$ $14-\mathrm{Na}_{2} \mathrm{O} 5-\mathrm{K}_{2} \mathrm{O} 5-\mathrm{Ag}_{2} \mathrm{O} 7 \mathrm{wt} . \%$, as it has been presented in detail in our previous work (Chatzistavrou et al., 2010; Chatzistavrou et al., 2012). After extended stirring, the final homogeneous solution follows a specific heat treatment: aging at $60{ }^{\circ} \mathrm{C}$, drying at $180{ }^{\circ} \mathrm{C}$ and stabilisation up to $700^{\circ} \mathrm{C}$. The fabricated material was in powder form with particle size $<35 \mu \mathrm{m}$.

\section{$E C M$}

The ECM hydrogels were provided by University of Pittsburgh. They were prepared from decellularised porcine urinary bladder matrix (UBM), as previously described (Freytes et al., 2004). Briefly, porcine urinary bladders from market weight pigs were harvested, and the urothelial, serosal and muscular layers were removed by mechanical delamination. The remaining tissue consisted of intact basement membrane and tunica propria, which was rinsed with deionised water and then treated with $0.1 \%$ peracetic acid $/ 4 \%$ ethanol on an orbital shaker at $300 \mathrm{rpm}$ for $2 \mathrm{~h}$. The UBM was then rinsed twice with phosphate buffered saline (PBS) for $15 \mathrm{~min}$ each followed by two rinses of 15 min in deionised water. UBM samples were frozen and lyophilised for use in hydrogel preparation (Freytes et al., 2008; Hong et al., 2011). In brief, lyophilised ECM scaffolds were powdered using a Wiley Mill and filtered through a 40-mesh screen. The comminuted ECM was then enzymatically digested in a solution of $1 \mathrm{mg} / \mathrm{mL}$ porcine pepsin (Sigma Aldrich, St. Louis, MO) in $0.01 \mathrm{~N} \mathrm{HCl}$ under a constant stir rate for $72 \mathrm{~h}$ at room temperature. ECM pepsin digest stock solutions of $10 \mathrm{mg} \mathrm{ECM} / \mathrm{mL}$ (dry weight) were frozen until use in subsequent experiments. Gelation was induced by neutralising the $\mathrm{pH}$ and salt concentration of the pepsin digest at $4{ }^{\circ} \mathrm{C}$ followed by warming to $37^{\circ} \mathrm{C}$. Neutralisation was accomplished by the addition of one-tenth the digest volume of $0.1 \mathrm{~N} \mathrm{NaOH}$, one-ninth the digest volume of $10 \times \mathrm{PBS}$, and then diluting to the desired final ECM concentration with $1 \times$ PBS while on ice. The neutralised digest (pre-gel) was then placed in a non-humidified incubator heated to $37^{\circ} \mathrm{C}$ for $1 \mathrm{~h}$, after which, a hydrogel had formed. ECM concentration of $10 \mathrm{mg} / \mathrm{mL}$ was prepared.

\section{$A g-B G / E C M$}

Pre-gel was mixed by pipetting with Ag-BG powder. The Ag-BG was incorporated into ECM at ratio 1:1 in wt.\% 
(Ag-BG/ECM). The Ag-BG/ECM was observed injectable through a syringe and $27 \mathrm{G}$ needle to subjectively determine injectability.

The extracts of Ag-BG/ECM and ECM alone were collected by incubating them into cell culture medium at equal volumes for $24 \mathrm{~h}$ at $37^{\circ} \mathrm{C}$. The extracts were collected after centrifuging. Undiluted extracts of all tested materials (1 mL for each material) were serially diluted (to 1:2,1:4 and $1: 8-\mathrm{v}: \mathrm{v}$ ) for the assessment of potential dose-response effects. Cell culture medium free of materials' extracts and incubated under the same conditions was used as negative control at all cell culture studies (UNTREATED). The biological response of the DPSCs on the prepared dilutions and the extracts-free medium was studied.

\section{Cell culture-Determination of cell viability, proliferation and cell apoptosis \\ Viability}

The laboratory of Dr. Kaigler at the University of Michigan kindly provided DPSCs. DPSCs were isolated applying that pulp tissue was gently separated from the crown and root, and subsequently digested in a solution of $3 \mathrm{mg} / \mathrm{mL}$ collagenase type I (Sigma, St. Louis, MO, USA) and $4 \mathrm{mg}$ / $\mathrm{mL}$ dispase (Sigma, St. Louis, MO, USA) for $1 \mathrm{~h}$ at $37^{\circ} \mathrm{C}$. Single-cell suspensions were obtained by passing the cells through a $70-\mathrm{mm}$ strainer (Falcon). Single-cell suspensions $\left(0.5\right.$ to $1.0 \times 10^{3} /$ well $)$ were seeded onto 6 -well plates (Costar) containing alpha modification of Eagle's medium (GIBCO/BRL) supplemented with $15 \%$ foetal bovine serum (FBS; Hyclone), $100 \mathrm{U} / \mathrm{mL}$ penicillin and $100 \mathrm{mg} /$ $\mathrm{mL}$ streptomycin (Sigma, St. Louis, MO, USA), and incubated at $37^{\circ} \mathrm{C}$ in $5 \% \mathrm{CO}_{2}$. The DPSCs were confirmed to be actually stem cells according to the methods described previously. DPSCs were then cultured for $24 \mathrm{~h}$ at $37^{\circ} \mathrm{C}$ on 96 -well plates with density $5 \times 10^{3}$ cells/well. They were cultured with the different dilutions of the extracts and the extract-free medium (UNTREATED). The cell viability was evaluated using the cell counting kit-8 (CCK-8) assay and repeated five times for each sample. The dilution of the extracts of the samples, at which DPSCs showed the highest viability, was used at all the experiments presented in this work.

\section{Proliferation}

The proliferation of the DPSCs was evaluated. DPSCs were in culture with the extracts of the samples at the specific dilution with the highest cell viability and compared with the UNTREATED. DPSCs $\left(1.0 \times 10^{3}\right.$ cells/well $)$ expanded ex vivo and seeded onto five $96-$ well plates separately. After $1,3,5$ and 7 days of culture, CCK-8 assay was used and repeated four times to evaluate the cell proliferation. During the culture, the morphology of DPSCs in each group was recorded by Nikon optical microscopy.

\section{Cell apoptosis: Flow cytometry}

Cell apoptosis rate was observed by flow cytometry. DPSCs cultured for $24 \mathrm{~h}$ at $37{ }^{\circ} \mathrm{C}$ with the extracts of Ag-BG/ $\mathrm{ECM}$ and ECM alone at the dilution with the highest cell viability and also untreated cells as negative control were stained with FITC Annexin V Apoptosis Detection Kit (BD Pharmingen) according to the manufacturer's instructions.
Stained cells were analysed by the Beckman Coulter MoFlo $^{\circledR}$ Astrios $^{\mathrm{TM}}$ flow cytometry system. Viable cells were negative for both PI and annexin V-FITC; apoptotic cells were positive for annexin V-FITC and negative for PI, whereas late apoptotic dead cells displayed strong annexin V-FITC and PI labelling. Non-viable cells, which underwent necrosis, were positive for PI but negative for annexin V-FITC. The cell apoptosis experiments were repeated three times.

\section{Effects of Ag-BG/ECM and ECM on stem cells markers profile}

Immunofluorescence staining

DPSCs were subcultured on 12-chamber slides $\left(2.0 \times 10^{4} /\right.$ well, second passage) and grown to $80 \%$ confluence. The cells were then incubated for $24 \mathrm{~h}$ at $37^{\circ} \mathrm{C}$, with the extracts of the materials at the dilution with the highest viability as well as the extract-free medium. Standard immunofluorescence methods were performed to detect potential changes in stem cell markers profiles. Briefly, DPSCs were initially fixed in $4 \%$ paraformaldehyde and the no-specific antigens were blocked with PBS containing $10 \%$ bovine serum albumin at room temperature for $1 \mathrm{~h}$. The cells were then incubated with diluted $(1: 50)$ primary antibody CD73 (Biolegend), CD90 (BD Pharmingen) and CD105 (Biolegend) overnight at $4{ }^{\circ} \mathrm{C}$, washed with PBS and subsequently incubated with fluoresceinconjugated secondary goat anti-mouse polyclonal antibody (Invitrogen) at room temperature in the dark for $1 \mathrm{~h}$. DAPI (Invitrogen) staining was then performed in the dark for 5 min. After being washed with PBS, the slides were analysed using a fluorescence microscope (Olympus BX51, Tokyo, Japan).

\section{Flow cytometric study}

In order to evaluate potential changes in the mesenchymal phenotype of the DPSCs after being exposed to the Ag$\mathrm{BG} / \mathrm{ECM}$ and $\mathrm{ECM}$ diluted extracts, the surface antigens of DPSCs were analysed by flow cytometry. Cells were trypsinised and incubated in PBS for $60 \mathrm{~min}$ with fluorescein conjugated antibodies against CD73 (Brilliant Violet421, Biolegend), CD90 (FITC, BD Pharmingen), CD105 (PE, Biolegend). The flow cytometry analysis of cells was carried out using Beckman Coulter MoFlo ${ }^{\circledR}$ Astrios $^{\mathrm{TM}}$ flow cytometry system, with 500,000 events being counted for each case. The procedure was repeated three times.

\section{DPSCs odontogenic differentiation}

Previous studies of solid polymer scaffolds have shown that differentiation of DPSC may be stimulated by the presence of dentine (Sakai et al., 2011). In our study, we used sterilised pulpless tooth slice incubated in culture medium to stimulate the odontogenic differentiation. DPSCs in $1 \times 10^{5}$ cells were centrifuged and the fabricated pellet was mixed with Ag-BG/ECM and ECM separately. Then, each of the complex mixture of cells with material was seeded in the hole of the tooth slice. Cells alone were seeded in tooth slice and cells only without the present of tooth slice were also seeded on the well plate. These two groups were designed as controls. Regular and 
Table 1: List of the DNA sequences of the primers used for the RT-PCR analysis.

\begin{tabular}{|c|c|c|c|}
\hline Gene name & 5'-squence-3' & Product size (bp) & GenBank number \\
\hline \multirow{2}{*}{ GAPDH } & Forward: GCAAATTCCATGGCACCGTC & \multirow{2}{*}{819} & \multirow{2}{*}{ XM_003273723.2 } \\
\hline & Reverse: GGTCCACCACCCTGTTGCTA & & \\
\hline \multirow{2}{*}{ DMP-1 } & Forward: CTGTGCTCTCCCAGTAACCA & \multirow{2}{*}{159} & \multirow{2}{*}{ NM_004407.3 } \\
\hline & Reverse: CTGGGGTCTTCATTTGCCTG & & \\
\hline \multirow{2}{*}{ RUNX2 } & Forward: TCCCCGTCCATCCACTCTAC & \multirow{2}{*}{157} & \multirow{2}{*}{ NM_001024630.3 } \\
\hline & Reverse: CACCTGCCTGGCTCTTCTTA & & \\
\hline \multirow{2}{*}{ ALP } & Forward: GCGCAGGACAGGATTAAAGC & \multirow{2}{*}{246} & \multirow{2}{*}{ NM_014476.5 } \\
\hline & Reverse: TCCACTGCCACAGTCAATCC & & \\
\hline \multirow{2}{*}{ DSPP } & Forward: CATGGGCCATTCCAGTTCCTC & \multirow{2}{*}{152} & \multirow{2}{*}{ NM_014208.3 } \\
\hline & Reverse: TTCATGCACCAGGACACCAC & & \\
\hline
\end{tabular}

differentiation cell culture media were used for culture up to 21 days. The differentiation was measured applying RTPCR and Alizarin Red staining, following the procedure that has been reported elsewhere (Gronthos et al., 2000). The intensity of the staining was quantified by using image J. The DPSCs odontogenic differentiation study was repeated three times.

\section{$R T-P C R$}

Total RNA was isolated from cells after 21 days using TRIzol (Invitrogen, Carlsbad, CA), and $2 \mu \mathrm{g}$ of RNA was reverse transcribed with TaqMan reverse transcription reagents (Applied Biosystems, Branchbury, NJ), following the manufacturer's instructions. The resulting cDNA was then amplified by RT-PCR using AmpliTaq Gold DNA Polymerase (Applied Biosystems). RT-PCR amplifications were performed at $95{ }^{\circ} \mathrm{C}$ for $30 \mathrm{~s}, 60{ }^{\circ} \mathrm{C}$ for $30 \mathrm{~s}$ and $72{ }^{\circ} \mathrm{C}$ for $30 \mathrm{~s}$ using specific primers for GAPDH, DMP1, Runx2, ALP and DSPP. The design of the primers was based on published mouse cDNA sequences (Table 1).The RT-PCR products were subcloned into pGEM-T Easy vector (Promega, Madison, WI) and RNA expression was confirmed by sequencing.

\section{Antibacterial activity}

Equal volumes of Ag-BG/ECM and PBS, which was used as control, were mixed separately with $S$. mutans (ATCC 25175) and L. casei (ATCC 15008) (kindly provided by Dr. J.C. Fenno at the University of Michigan) and then incubated for $24 \mathrm{~h}$ at $37^{\circ} \mathrm{C}$. After $24 \mathrm{~h}$, each mixture was diluted serially $\left(10^{-1}, 10^{-2}, 10^{-3}, 10^{-4}\right.$ and $\left.10^{-5}\right)$ and subsequently was plated on agar plates. All plates were incubated for $48 \mathrm{~h}$ at $37^{\circ} \mathrm{C}$, and the developed colonies were counted.

\section{Pulp/dentin in vivo formation}

An approved UCUCA protocol for small animals was applied during this study. In particular, approximately $1.0 \times 10^{7}$ DPSCs cells (third passage) were cultured with $\mathrm{Ag}-\mathrm{BG} / \mathrm{ECM}$ extracts in 1/4 dilution and, as a control, the same density of DPSCs cells were cultured with extract-free medium. Both groups of DPSCs cells were then co-cultured separately with $40 \mathrm{mg}$ of hydroxyapatite (HA) powder for $3 \mathrm{~h}$, before they were implanted into the dorsal surfaces of 10-week-old mice with severe combined immunodeficiency (CB-17 scid mice, NIH-bgnu-xid; Harlan-Sprague-Dawley; Harlan Laboratories, Indianapolis, IN). Six scid mice were used for the experiment. Each nude mouse received both experimental and control group cells/materials in opposite sites. Thus, we totally analysed six different samples for the experimental group and six different samples for the control group. The implants were recovered after 8 weeks, then fixed with $4 \%$ formalin, decalcified with buffered $10 \% \operatorname{EDTA}(\mathrm{pH} 8.0)$, and finally they were embedded in paraffin. Sections $(5 \mathrm{~mm})$ were deparaffinised and stained with haematoxylineosin. Dentin formation was quantified using image J (NIH Image software).

The immunohistochemical staining was carried out according to the manufacturer's instructions of VECTASTAIN ABC system, 3,3' Diaminobenzidine (DAB) was applied as the chromogen. Primary antibodies used are: DSP (gift of Dr. Simmer at the University of Michigan; dilution 1:500), nestin (Novus USA; dilution 1:200), VEGF (Chemicon Millipore; dilution 1:200) and Anti-nuclei antibody, clone 235-1 (Chemicon Millipore; dilution 1:500).

\section{Statistical analysis}

SPSS software was used (version 13.0; SPSS, Chicago, IL, USA). Statistical analysis was performed using the paired Student's $t$ test. The level of statistical significance was $p<0.05$.

\section{Results}

\section{Cell viability, proliferation and cell apoptosis}

The cell viability of DPSCs in culture with different dilutions of the extracts of the Ag-BG/ECM and ECM alone was evaluated. It was found that cell viability was slightly inhibited for undiluted extracts of both materials. However, this inhibition was not significant compared to the controls. In contrast, there was increase in cell viability for both materials at 1:2, 1:4 and 1:8 dilutions. However, the cell viability is statistically significant compared to the control only for Ag-BG/ECM at dilutions 1:4 and 1:8 $(p<0.005)$. The 1:4 dilution for both materials showed 
A

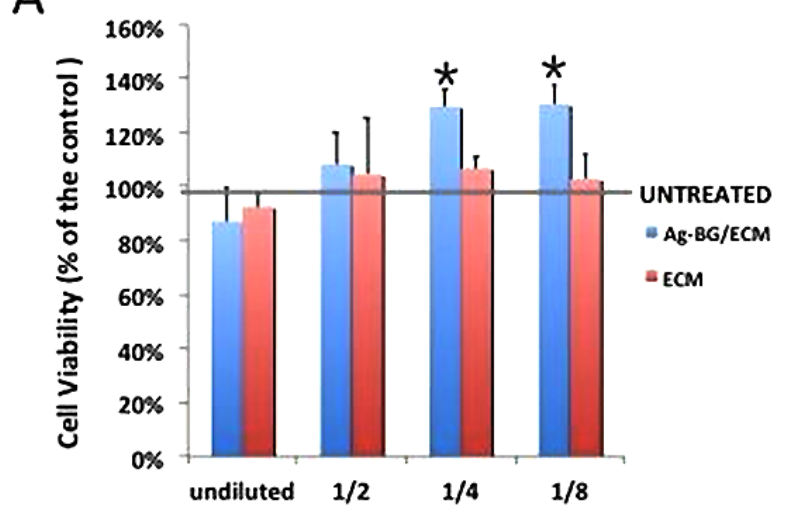

B

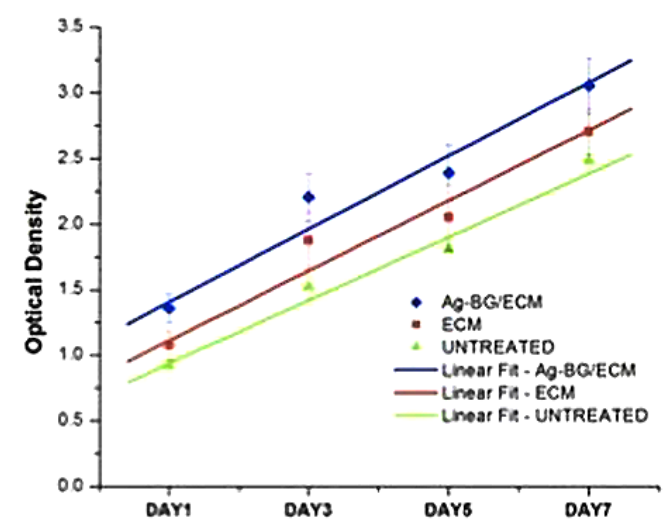

C DPSCS + Ag-BG/ECM X DILUTION $10^{\circ} \mathrm{Be}$
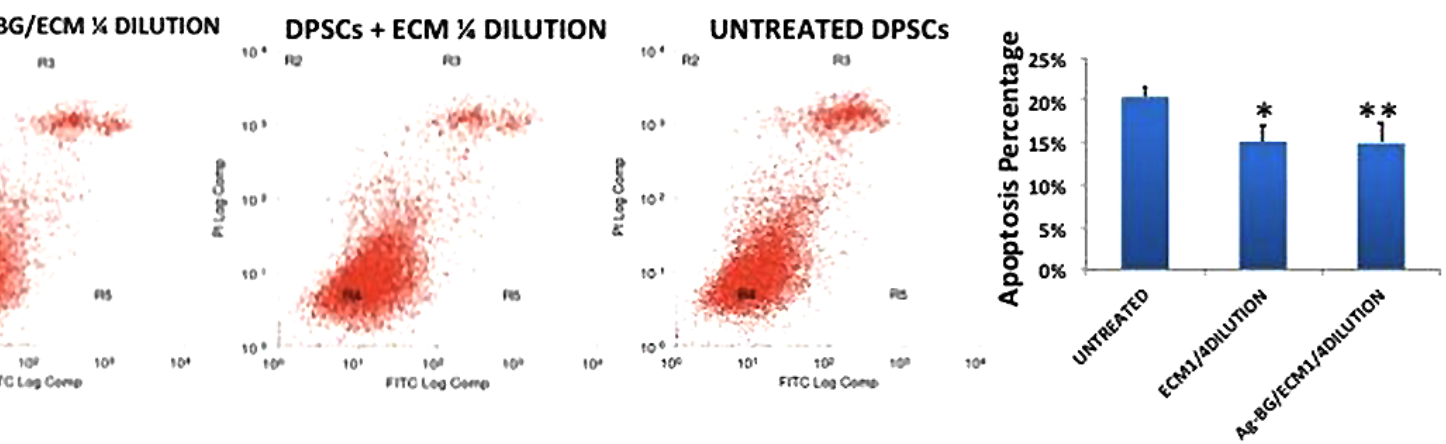

Fig. 1. (A) The viability of DPSCs as percentage of live cells of the extract-free control was measured after $24 \mathrm{~h}$ of culture and compared with the extracts of Ag-BG/ECM and ECM alone at different dilutions (* = statistically significant difference between control and Ag-BG/ECM group $(p<0.05)$ ). (B) Proliferation of DPSCs after 1, 3, 5 and 7 days in culture with Ag-BG/ECM and ECM extracts at 1:4 dilution and control. (C) Statistical results of apoptosis rate derived from flow cytometry study showed that DPSCs treated with 1:4 diluted extracts of Ag-BG/ECM and ECM have significant lower apoptotic rate than the control group $(*=$ statistical significant difference between control and $\mathrm{ECM} ; * *=$ statistical significant difference between control and Ag-BG/ECM $(p<0.05))$.

slightly higher cell viability compared to 1:8 dilution and it was finally chosen as the working dilution of both materials in the rest of our studies (Fig. 1A).

Cell proliferation showed a linear increase from day one to day seven of culture for both materials and the control group (cells without treatment). The proliferation rate was calculated similarly in all cases. However, at each time point the cell proliferation in the Ag-BG/ECM samples was higher compared to the respective ECM samples. ECM samples showed higher cell proliferation compared to controls (Fig. 1B).

Apoptosis rate of DPSCs was found to be significantly lower in case of culture with the diluted extracts of Ag-BG/ ECM and ECM $(p<0.05)$ compared to the control group (cells without treatment) (Fig. 1C), while there was no significant difference in case of $\mathrm{Ag}-\mathrm{BG} / \mathrm{ECM}$ and $\mathrm{ECM}$ alone $(p>0.05)$.

\section{Stem cells markers profile}

The DPSCs expressed MSCs markers CD73, CD90 and CD105 when they were cultured for $24 \mathrm{~h}$ with the extracts of the Ag-BG/ECM and ECM diluted at 1:4, as presented by immunofluorescence staining (Fig. 2A). Their phenotypical characteristics remain unchanged compared to the control group (cells without treatment). Positive expression of the MSCs markers CD73, CD90 and CD105 was also found by flow cytometry for all samples (Fig. 2B). There is no significant difference in the positive expression percentage of MSCs markers among the three different groups (Ag-BG/ECM, ECM and control) (Fig. 2B).

\section{DPSCs odontogenic differentiation}

The DPSCs showed odontogenic differentiation after 21 days in culture in the presence of a tooth slice alone or in the presence of a tooth slice with Ag-BG/ECM and ECM. However, the calcium deposition and gene expression varied significantly among the different groups (Fig. 3). No signs of differentiation were observed at the DPSCs without the presence of a tooth slice. The tooth slice with Ag-BG/ECM/DPSCs showed significantly higher calcium deposition compared to the tooth slice with ECM/DPSCs and to the tooth slice/DPSCs alone (Fig. 3A). The odontogenic differentiation markers DMP1, Runx2 and ALP are up-regulated significantly in the tooth slice with Ag-BG/ECM/DPSCs compared to other groups, but no DSPP is detected (Fig. 3B). The addition of differentiation medium (incorporating Ascorbic acid, Dex and $\beta$-Glycerophosphate) and culture for 10 days enhanced 
A

DPSCS +Ag-BG/ECM $1 / 4$ DILUTION

DPSCS + ECM $1 \frac{1}{4}$ DILUTION

UNTREATED DPSCS
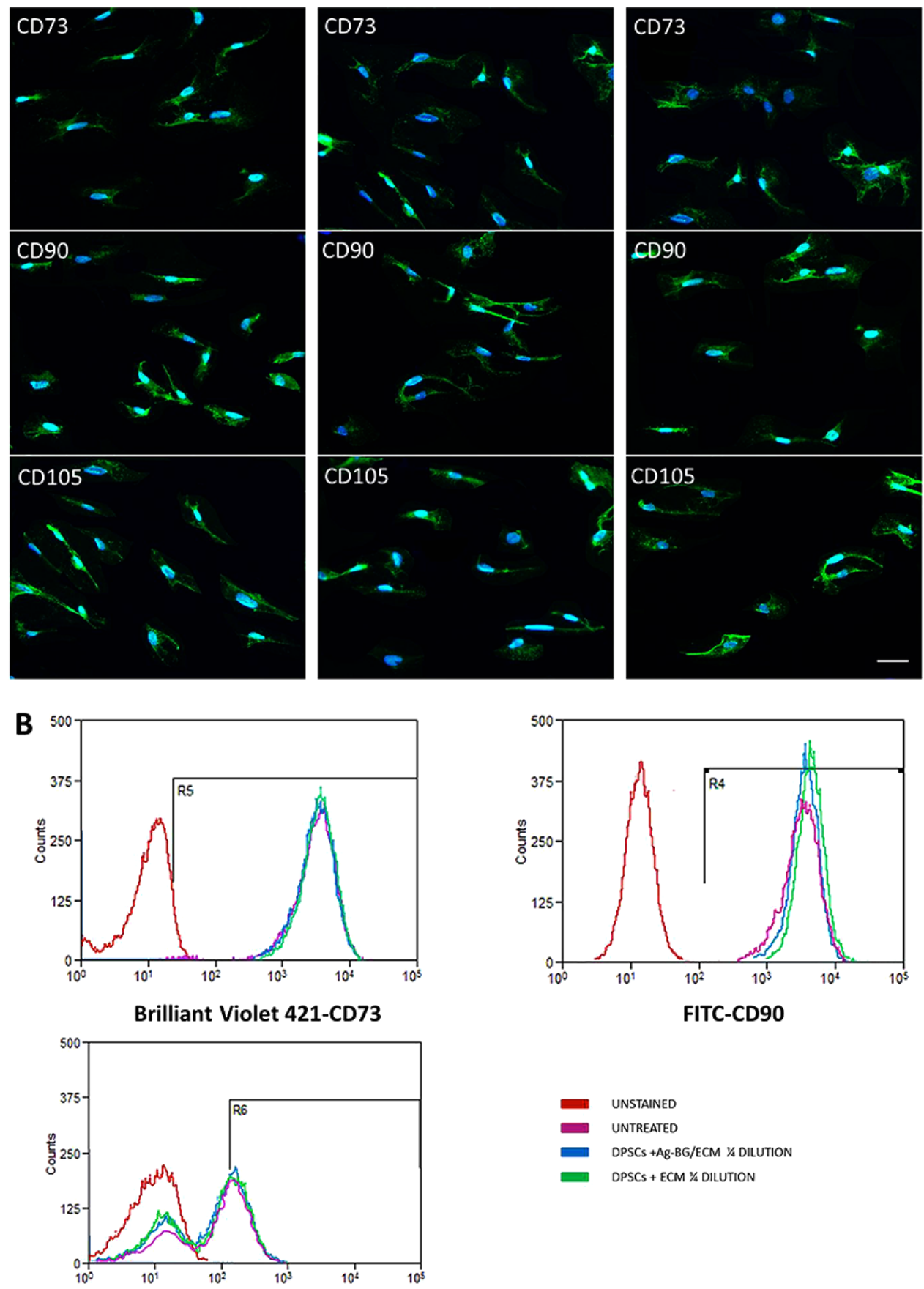

FITC-CD90
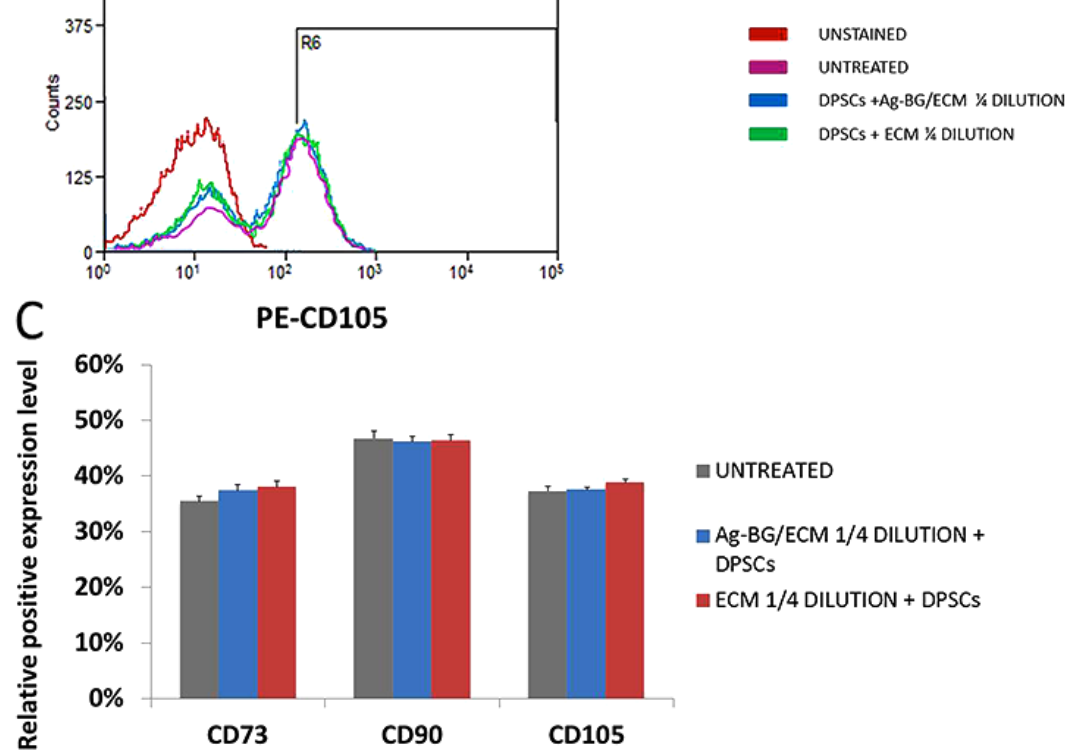

— UNTREATED

- Ag-BG/ECM 1/4 DILUTION +

DPSCS

- ECM 1/4 DILUTION + DPSCS

Fig. 2. (A) Immunofluorescence staining applied to observe the expression of the MSCs markers CD73, CD90 and CD105 in DPSC $($ bar $=200 \mu \mathrm{m})$. (B) Flow cytometry study showed the positive expression of MSCs markers CD73, CD90 and CD105 in DPSC (C) Statistical analysis of the flow cytometry results. 
A DPSCs SLICE+DPSCS SLICE+ECM+DPSCS SLICE+Ag-BG/ECM+DPSCS
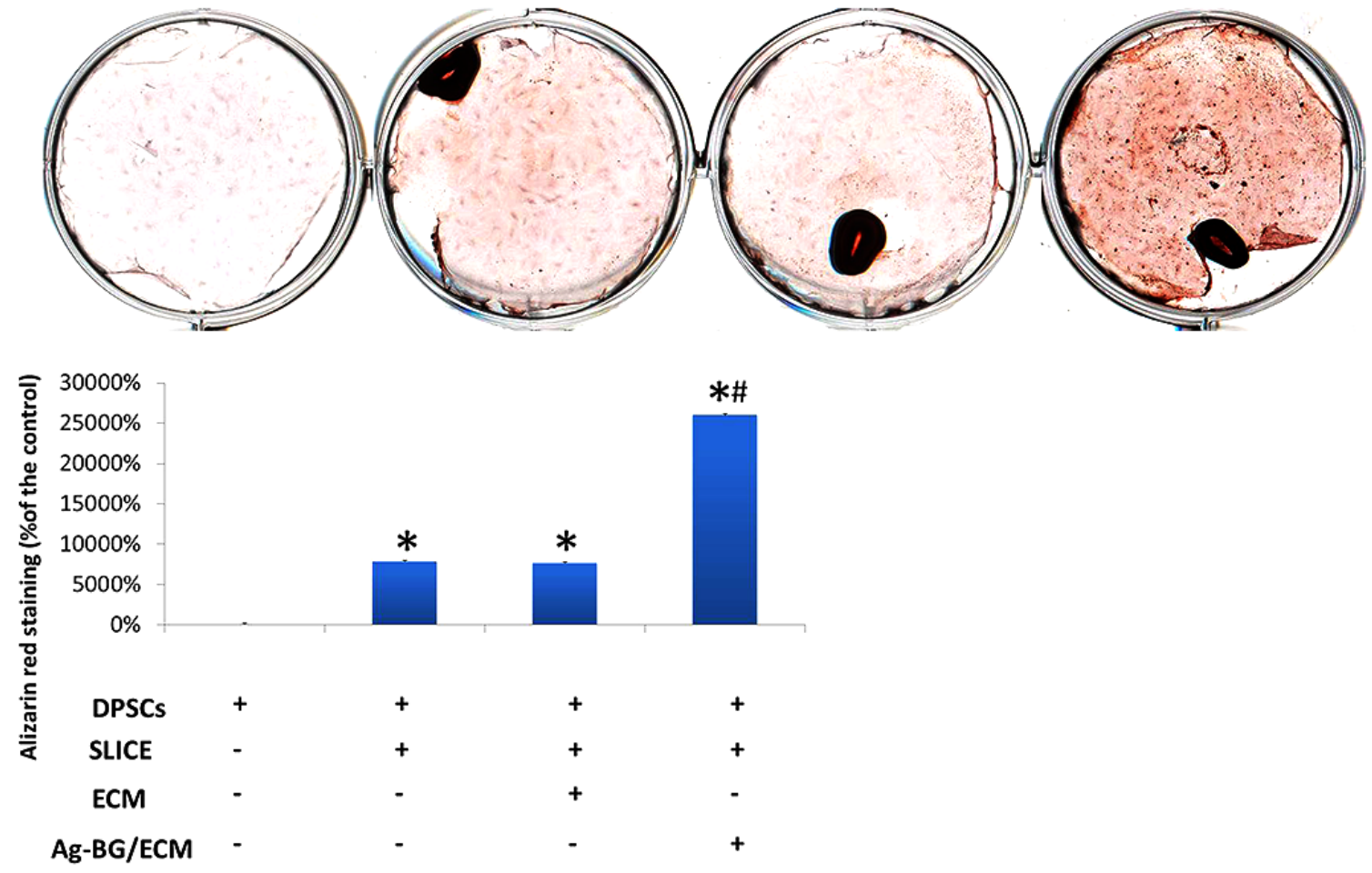

B
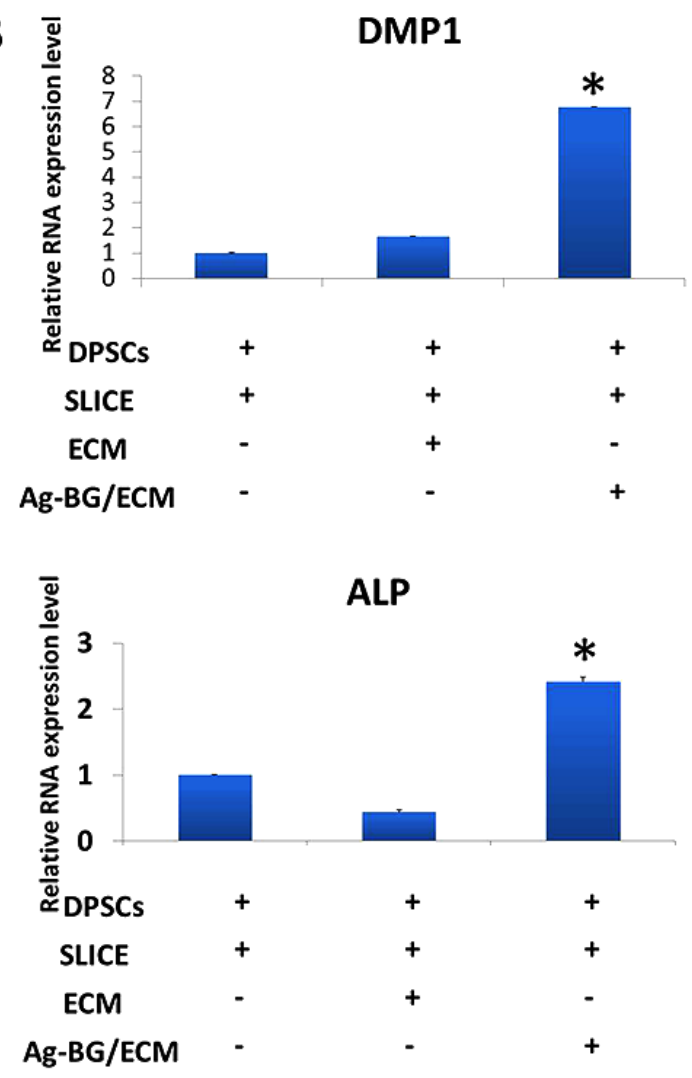

*\#

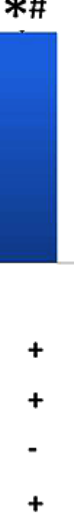

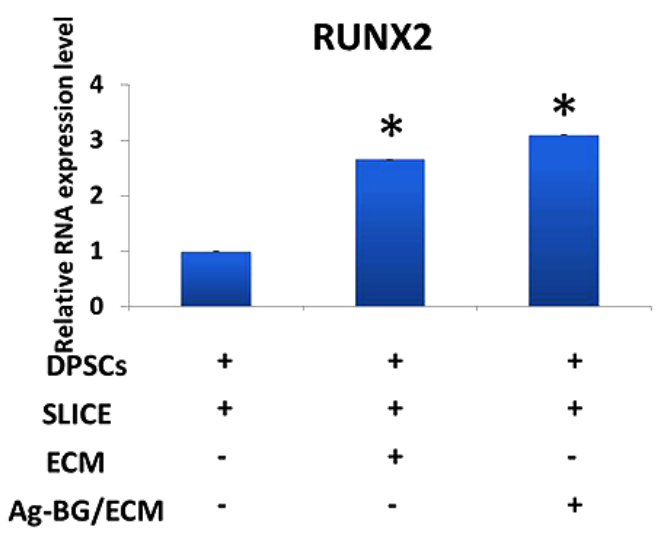

C

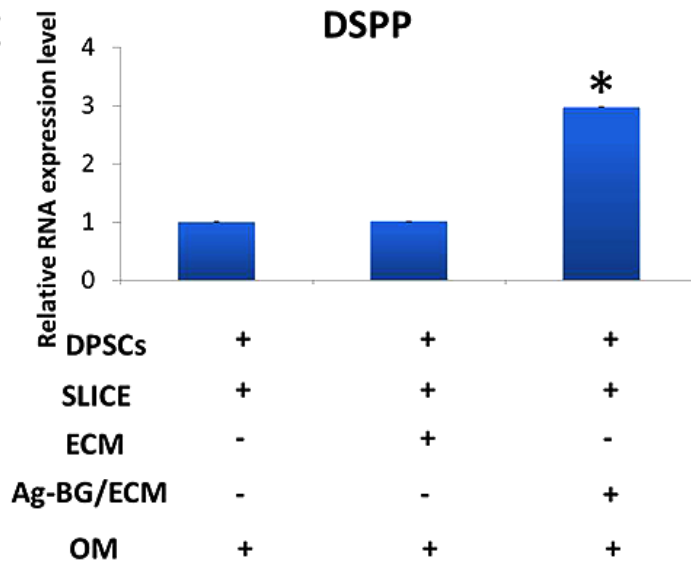

Fig. 3. (A) Odontogenic differentiation by alizarin red staining $(*=$ statistical significant difference between the DPSCs alone and the other three groups) (\# = statistical significant difference between the Ag-BG/ECM and the other three groups) $(p<0.05)$. (B) RT-PCT analysis showed the expression levels of the odontogenic related markers (DMP-1, RUNX2 and ALP) (* = statistical significant difference compared to the control) $(p<0.05)$. (C) RT-PCR results on DSPP expression after culture for 10 more days with mineralisation medium $(*=$ statistical significant difference compared to the tooth slice/DPSCs group) $(p<0.05)$. 
A

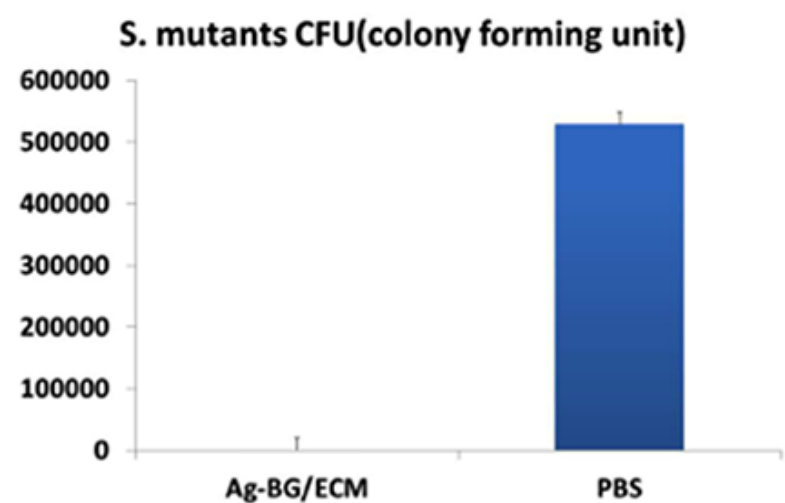

B

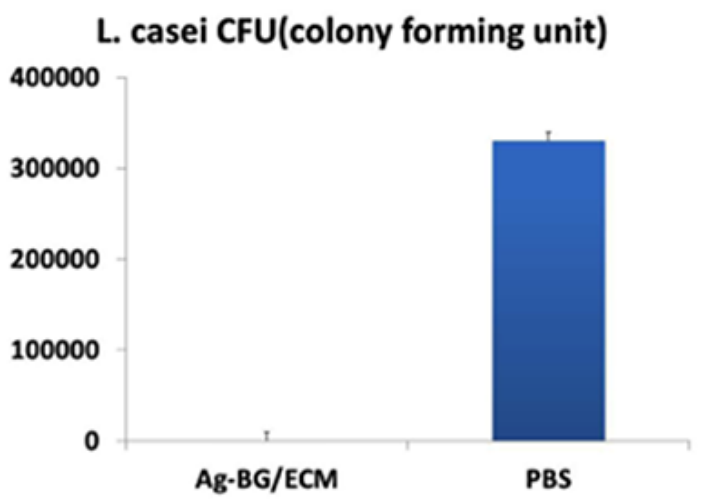

Fig. 4. Antibacterial activity of Ag-BG/ECM against S. mutans (A) and L.casei (B). No colonies growth is found in the presence of $\mathrm{Ag}-\mathrm{BG} / \mathrm{ECM}$.
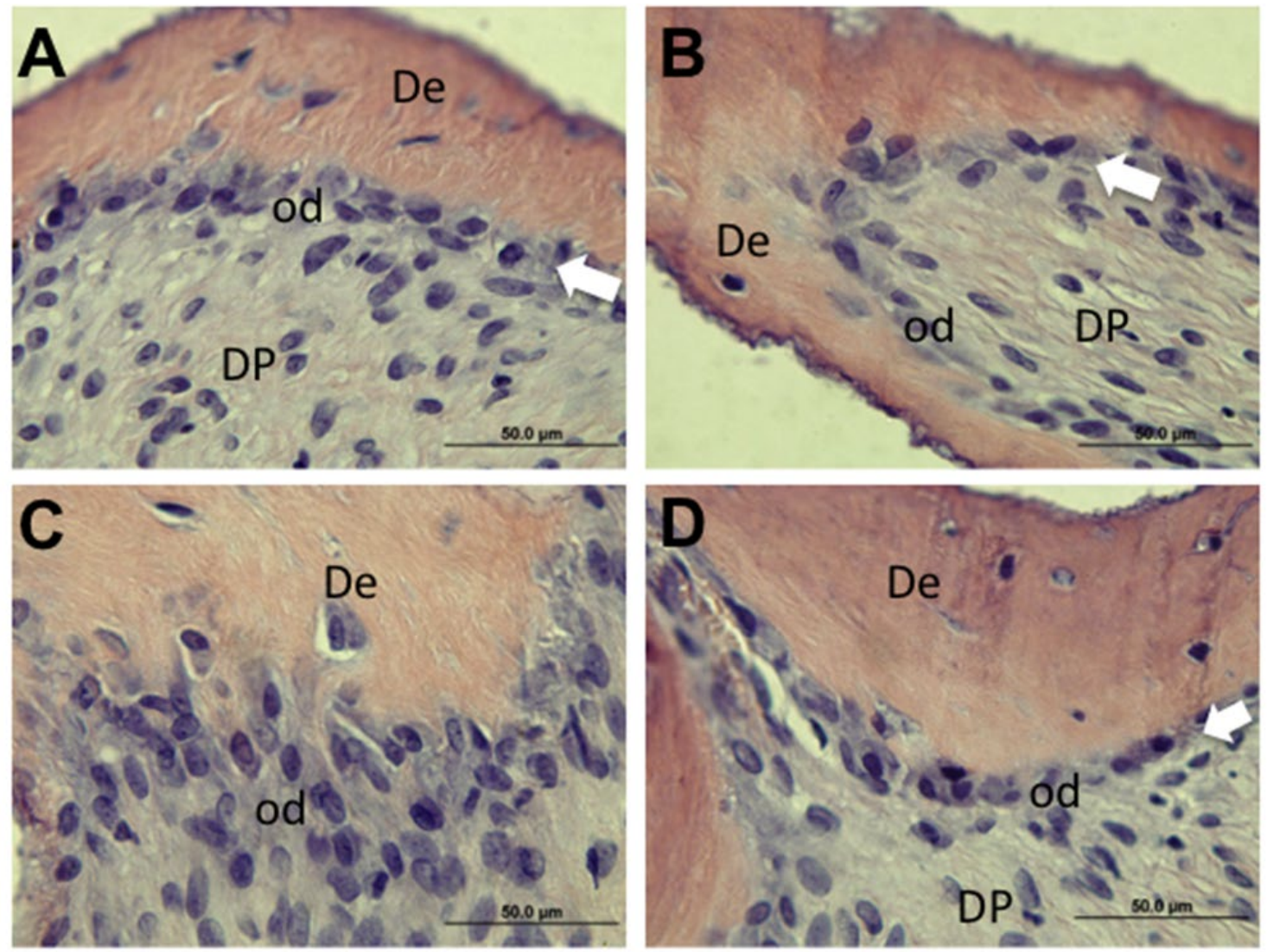

Fig. 5. (A-D) The regenerated mineralised tissue shows a dentin-like (De) morphology with the collagenous matrix being deposited perpendicular to the odontoblast-like (od) layer. The odontoblast-like cells lining the regenerated dentin-like tissue (white arrows) present characteristic morphological features of odontoblasts. The new dentin/ pulp like complex includes also cells with fibroblastic morphology similar to dental pulp (DP) cells underlying the odontoblast-like cells. All four images were taken at $100 \times$ magnification.

the expression of DSPP. Tooth slice with Ag-BG/ECM/ DPSCs showed significant increase of DSPP expression compared to the other groups (Fig. 3C).

\subsection{Antibacterial activity}

The antibacterial activity of Ag-BG/ECM against $S$. mutans and L.casei was evaluated (Fig. 4A-B). Significantly, there is no bacteria growth after $24 \mathrm{~h}$ of co-culture. This activity is significant different compared to the control (PBS coculture with bacteria).

\section{Pulp/dentin in vivo formation}

Both groups (the DPSCs cultured with Ag-BG/ECM extracts and mixed with hydroxyapatite (HA) scaffold constitute the experimental group; the DPSCs cultured with extract-free medium and HA constitute the control group) after eight weeks of implantation induce the formation of pulp/dentin complex. The formed tissues show dentin-like morphology with the collagenous matrix being deposited perpendicular to the odontoblast-like layer when they are observed on the surface of the hydroxyapatite particles 


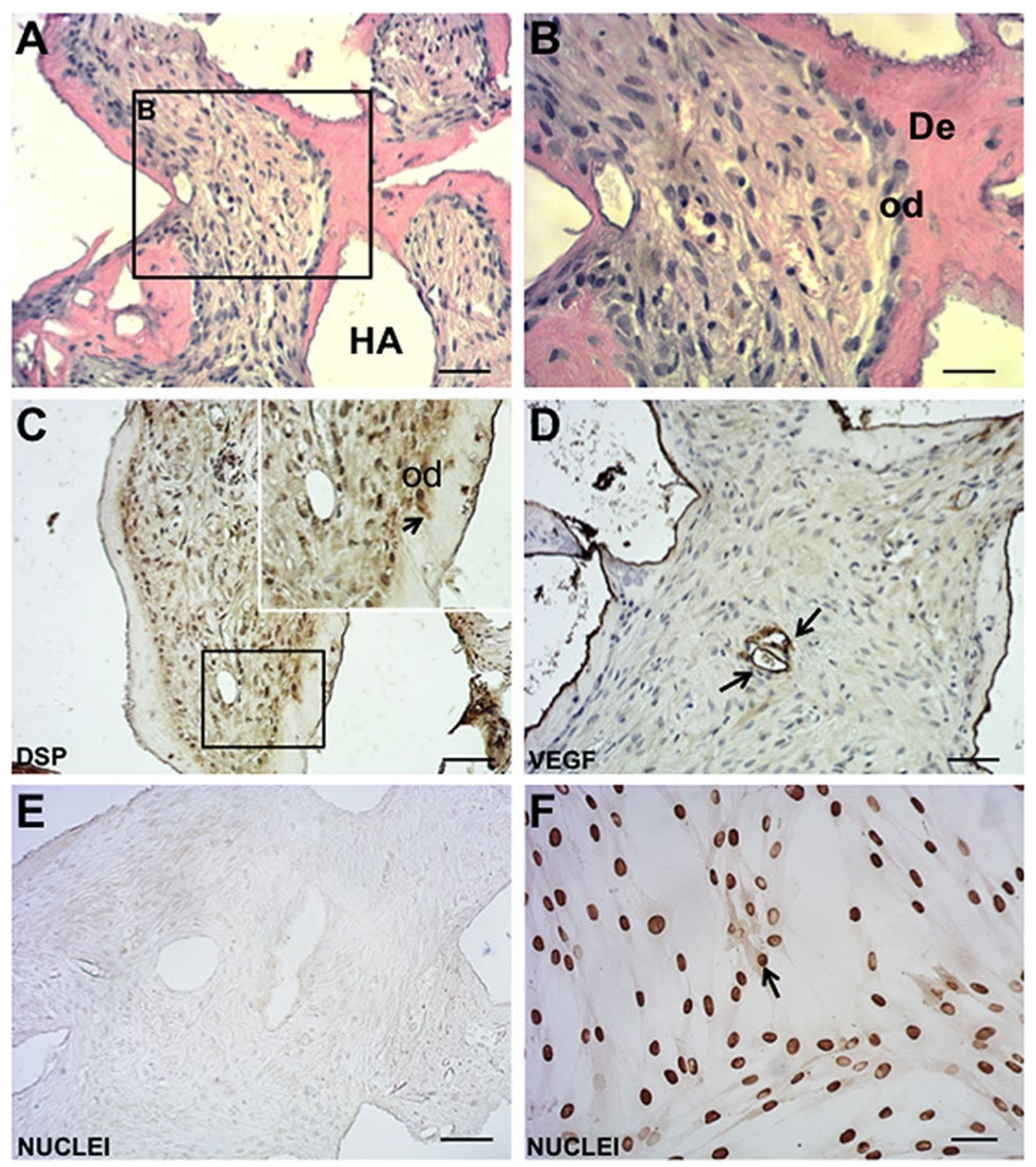

Fig. 6. (A, B) New dentin/pulp like complex was formed by both groups used (the DPSCs cultured with Ag-BG/ ECM extracts and HA constitute the experimental group; the DPSCs cultured with extract-free medium and HA constitute the control group). The HA carrier surfaces were lined with a dentin-like matrix (De), and an interface layer of odontoblast-like (od) cells. A magnified view of the dentin matrix (De) highlights the odontoblast-like layer (od) and odontoblast processes (B). Abbreviations: HA, hydroxyapatite; (C, D) New dentin/pulp like complex showed positive staining for DSP (C) and VEGF (D); Higher magnification of the dentin-like regenerated tissue reveals positive signal in odontoblast-like cells processes (arrow); (E, F) New dentin/pulp like complex showed negative staining for the anti-nuclei human antibody eight weeks after implantation (E). Immunohistochemistry with the anti-nuclei human antibody on the human DPSCs was used as a positive control for this experiment $(\mathbf{F})(\mathrm{Bar}=200$ $\mu \mathrm{m}$ in $\mathbf{A}-\mathbf{E}, 20 \mu \mathrm{m}$ in $\mathbf{F})$.

(Fig. 5 and Fig. 6A-B). The dental mineralising cells facing dentin-like matrix display protruding cytoplasmic processes into the matrix and are positively immunostained for DSP (Fig. 6C), the main phenotypic marker of odontoblasts. This dentin-like matrix is interfaced with a pulp-like interstitial tissue that includes blood vessels (VEGF positive) (Fig. 6D). The new-formed dentin/pulplike complex shows negative response on the anti-human nuclei antibody staining at eight weeks after implantation (Fig. 6E) compared to anti-human nuclei antibody positive control staining (Fig. 6F). Of relevance, a significant higher number of odontoblast-like cells immunopositive for DSP is observed for the $\mathrm{Ag}-\mathrm{BG} / \mathrm{ECM}$ treated group compared to control group (Fig. 7A-B). Moreover, the Ag-BG/ECM treated group induces significantly higher dentin formation compared to control group (Fig. 7C-E), which is the 

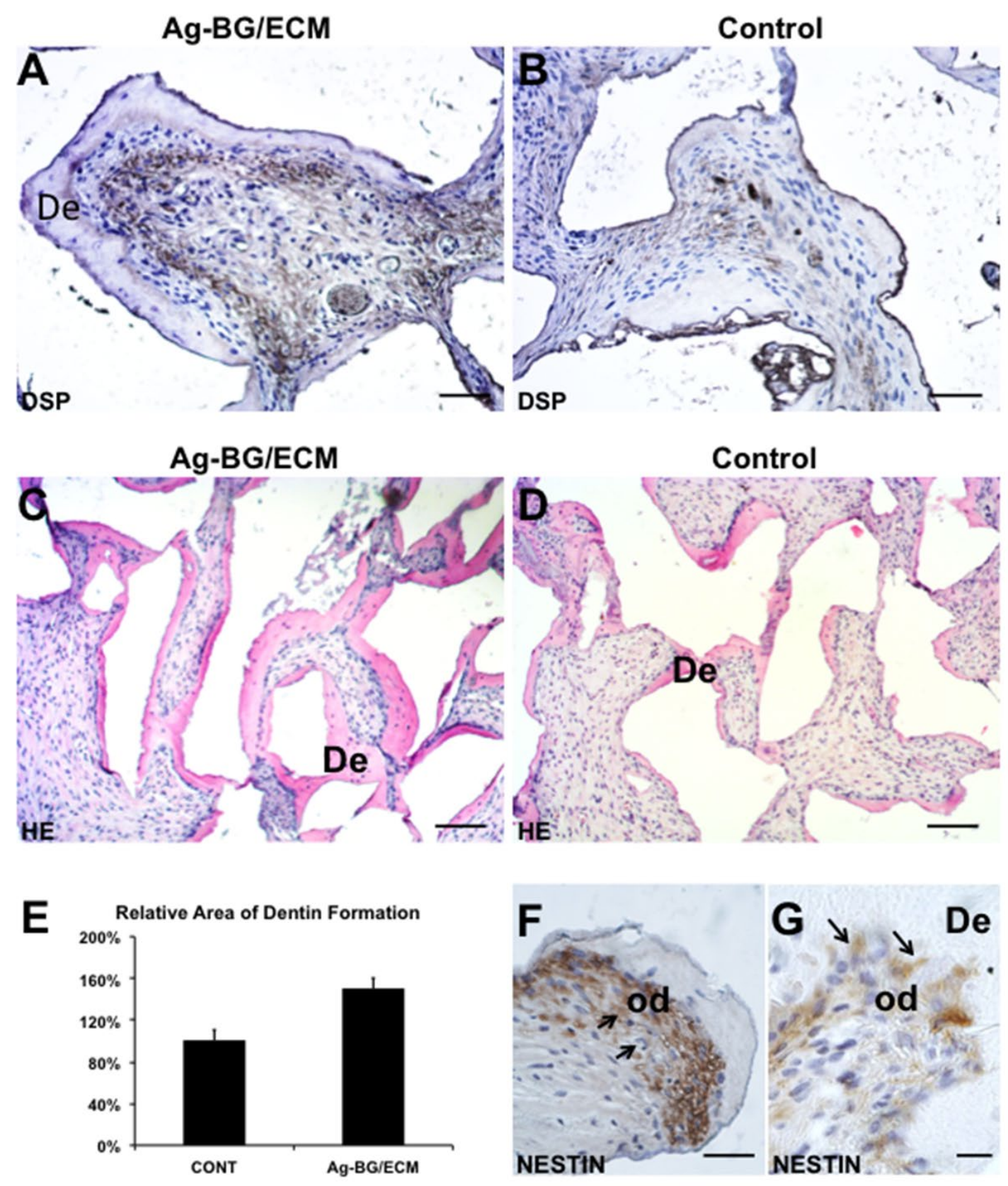

Fig. 7. (A-E) Comparison of dentin/pulp complex formation between Ag-BG/ECM treated group and control group. The Ag-BG/ECM treated group showed stronger DSP positive staining $(\mathbf{A})$ and higher amounts of dentin formed $(\mathbf{C})$ compared to the control group $(\mathbf{B}, \mathbf{D}$ and $\mathbf{G})(*=$ statistical significant difference compared to the control) $(p<0.05)$. Nestin staining was found in dental pulp cells in proximity to dentin-like matrix (De) (F) and signal was stronger in odontoblast-like cells (od) $(\mathbf{F}, \mathbf{G})$ and localised within their cells processes (arrows) (G) (Bar $=200 \mu \mathrm{m}$ in $\mathbf{A}-\mathbf{D}$ and $\mathbf{F}, 20 \mu \mathrm{m}$ in $\mathbf{G})$.

principal outcome of this work. The odontoblast-like cells lining the regenerated dentin-like tissue show also positive immunoreactivity for nestin (Fig. 7F-G) confirming their odontoblast-like phenotype.

\section{Discussion}

There is increasing interest in designing innovative treatment options to treat dental pulp infections with minimal removal of tooth structure and replacement with natural live tissue (Murdoch-Kinch and McLean, 2003). Moreover, it has been reported that the fabrication of innovative bioactive/biomimetic ion-releasing restorative materials, capable of re-mineralising the mineral-depleted dental tissues, has become one of the main targets in dental biomaterials research (Sauro et al., 2013). Thus, approaches using scaffolds and/or cells have been evaluated mainly for their regenerative potential in healing dental defective tissues (Ringe et al., 2002).

Enhanced and/or guided dentin tissue regeneration is an essential part needed for success of dental reparative 
procedures. Obtaining sound reparative dentin will certainly maximise the outcome of dental procedures. The success of dentin/pulp regeneration for root canal treatments depends on the development of suitable scaffolding materials as carriers for DPSCs. Towards this long term goal, our study describes the fabrication and characterisation of a novel bioactive and injectable material Ag-BG/ECM with strong anti-bacterial properties and enhanced cell differentiation, mineralisation potential and dentin formation. Furthermore, this study shows that the integration of an Ag-doped silicate BG into the natural ECM hydrogel significantly enhanced DPSCs proliferation and differentiation. This approach is novel and promising, as it combines the synergetic properties of each component, leading to better biological, antibacterial and mineralisation activities of the composite Ag-BG/ECM scaffold than the individual components.

An important characteristic of the silicate bioactive glasses is their ionic degradation by products, which are soluble and have been observed to stimulate mineralised tissue formation through the activation of the expression of several genes associated with mineralised matrix deposition (Xynos et al., 2000) Consequently, if the ion release process of the $\mathrm{BG}$ could be controlled, then this could be critical to ensure desirable biological responses. The Ag-BG presents controlled ion release profile. The ion dissolution was constantly observed from Ag-BG for over 4 weeks, and no apparent burst release was observed on the first (Chatzistavrou et al., 2014).

DPSCs are odontogenic progenitor cells and have clonogenic abilities, rapid proliferation rates and multiple differentiation potentials (odontogenic, osteogenic and adipogenic), providing a suitable cell source for tissue regeneration (Gronthos et al., 2000). When DPSCs are used for pulp/dentin regeneration, their proliferation and odontogenic differentiation should be enhanced. An appropriate microenvironment that can facilitate cellmaterial interactions could be crucial for the achievement of these goals. Our data showed that when Ag-BG is incorporated into the ECM hydrogel, DPSCs had higher proliferation and lower apoptosis percentage compared to ECM alone and control, indicating that the ions released from the Ag-BG influence cellular proliferation and apoptosis. The released ions - such as calcium, phosphate and silicon - enhance differentiation and mineralisation of the cells through ion-mediated reactions, as also demonstrated in several other types of ion-eluting bioactive glass materials (Sachlos et al., 2003; Marelli et al., 2010). This action may also be important in triggering the odontogenic function of DPSCs. Indeed, we found that the expression levels of marker genes for odontogenic differentiation were all significantly higher in the Ag-BG/ ECM than the control. This is not the case when ECM alone is compared to the control.

In particular, the odontoblastic activity of the DPSCs was evaluated by measuring their ALP activity, Alizarin red stain level and mRNA level of cell differentiation markers. ALP has been used to evaluate osteo/odontoblastic activity in various engineered biomaterials, as it is considered an important phenotype of the bone and dentin forming cells (Hong et al., 2009; Nam et al., 2011). The influences of Ag-
$\mathrm{BG} / \mathrm{ECM}$ and ECM alone on the odontogenesis of DPSCs were examined by measuring the mRNA expression levels of ALP, RUNX2, DMP-1 and DSPP, which were chosen as markers for the odontogenic phenotype. The latter two genes are specific markers in odontogenesis as DMP-1 is accepted as key marker for odontoblasts in newly formed dentin (Narayanan et al., 2001) and DSPP is a well-known specific marker expressed by odontoblastic cells, while higher expression observed as dentin mineralisation progresses (Hanks et al., 1998). RT-PCR data confirmed that DPSCs treated with Ag-BG/ECM had up-regulated mRNA levels for all markers used when compared to the other groups. These data show that the biomimetic Ag-BG/ECM provides better chemical composition and microenvironment that significantly enhances proliferation, differentiation and biomineralisation of DPSCs.

$\mathrm{Ag}-\mathrm{BG}$ is a silicate-based glass with $\mathrm{Ca} / \mathrm{P}$ ratio close to 4 , capable of inducing apatite formation when immersed in simulated body fluid (SBF) due to the dissolution and subsequent protonation of the $\mathrm{Si}-\mathrm{O}$ groups to form silanols as seats for heterogeneous nucleation and crystallisation (Kim et al., 2010). Measurements of the ion release in suspension demonstrated that Ag-BG releases ions into its environment (Chatzistavrou et al., 2014). Ag-BG can therefore be considered as an efficient calcium and silicon source for remineralisation processes. Based on our previous results (Chatzistavrou et al., 2012), which showed that Ag-BG enhances the development of hydroxyapatite phase, we also postulate that the new material Ag-BG/ ECM will also induce apatite formation and consequently could develop strong bonds with the surrounding dentin. However, more research is necessary for the evaluation of this potential property combined with the evaluation of the mechanical properties of the developed bond.

Among other anti-bacterial agents, different forms of silver (Ag) have been previously incorporated into dental materials (Yoshida and Atsuta, 1999; Cheng et al., 2012; Zhang et al., 2012). Although these strategies have shown various degrees of success in inhibiting bacterial growth, the resulting modified materials lack bioactive properties that can induce remineralisation of the mineral-depleted dental tissue, repair and regeneration. In our study, Ag ions were incorporated into a silicate bioactive glass and this was combined into ECM hydrogel, obtaining an injectable material that enhances endogenous cells response and provides bacterial protection. Indeed, our Ag-BG/ECM material shows complete bactericidal effects against $S$. mutans and $L$. casei growth. The antibacterial action of the $\mathrm{Ag}-\mathrm{BG} / \mathrm{ECM}$ could be only attributed to the released Ag ions from the $\mathrm{Ag}-\mathrm{BG}$ and not to changes at the $\mathrm{pH}$ value. Our previous work (Chatzistavrou et al., 2014) presents in detail the ion release profile of this material and the calculated concentration of the released silver was higher than the minimum required for expressing antibacterial activity $(0.1 \mathrm{ppm})$ and well below the cytotoxic levels for human cells (1.6 ppm) (Saravanapavan et al., 2004). Similarly, the $\mathrm{pH}$ value remains at neutral level $(\sim 7.5)$ during a soaking time period more than a month. We are not expecting different properties in case of $\mathrm{Ag}-\mathrm{BG} / \mathrm{ECM}$ as ECM hydrogel is also neutralised before the incorporation of Ag-BG. Our ongoing studies aim to further characterise 
the anti-bacterial effects of Ag-BG/ECM using different biofilm assays.

There is extensive use of natural extracellular matrix scaffold (ECM) for regeneration of defected organs (Badylak, 2002; 2007). ECM scaffolds are being used extensively for generation of damaged tissues but also for whole organ regeneration (Badylak, 2004). However, it is still unclear if regeneration of defective tooth parts can be performed on a large scale (Mitsiadis and Papagerakis, 2011). In the short term, it may be more feasible to design and fabricate regenerative materials that enhance topically the regenerative potential of the defective dental tissues (Chatzistavrou et al., 2012). Towards this goal, we have also tested the regenerative properties of ECM hydrogel. Our data show that ECM induces cell proliferation and cell differentiation. We also show that Ag-BG integrated into ECM scaffolds result in strong bacterial growth inhibition. Of interest, the combined Ag-BG/ECM shows also enhanced cell proliferation and differentiation properties in addition to the improved anti-bacterial action.

Previous experiments have shown that transplantation of DPSCs, mixed with hydroxyapatite/tricalcium phosphate, formed an ectopic pulp-dentin-like tissue complex in nude mice (Gronthos et al., 2000). Our in vivo results show enhanced dentin and dental mineralising cells formation for those DPSCs treated with Ag-BG/ECM compared to the control group. These dental mineralising cells facing the newly formed matrix have the distinct phenotypic characteristic of odontoblasts expressing nestin and DSP. Therefore, we postulate that the released ions from the Ag-BG, combined with the released biomolecules of the natural ECM hydrogel and its inherent biological properties, may promote dentin regeneration. These data provide more evidence for the ability of this new material to promote odontogenic differentiation in vivo.

We therefore, postulate that Ag-BG/ECM may be used in the future for dental pulp treatment approaches, providing optimised dental pulp regeneration under bacteria-free conditions. The in vivo results indicate potential clinical applications of Ag-BG/ECM, as a dental material with unique properties of healing and regenerating dental tissues, while promoting bacteria-free conditions. Ag-BG can find applications in the restoration of dental lesions with direct or indirect pulp injury. This could significantly increase the lifetime of the restoration, leading to a breakthrough novel approach with superior outcome compared to the traditional currently used dental approaches. Even though, our studies highlight that Ag-BG/ECM demonstrates enhanced anti-bacterial and regenerative properties, while lacking any detectable toxicity, additional studies are necessary to examine in more detail the advantages of Ag-BG/ECM in vivo.

\section{Conclusion}

This study reports the fabrication and evaluation of novel bioactive and antibacterial material (Ag-BG/ECM) able to inhibit $S$. mutans and $L$. casei growth and to induce dental pulp cells proliferation and differentiation. The in vivo results support the potential use of $\mathrm{Ag}-\mathrm{BG} / \mathrm{ECM}$ in dental clinical applications with an emphasis on pulp treatment, as an injectable material for the restoration of lesions involving pulp injury. We believe that this initial study contributes to the field of regenerative dentistry, promoting minimally invasive approaches and provides foundation for future studies on Ag-BG/ECM material applications with clinical relevance.

\section{Acknowledgments}

This work is conducted during an established collaboration between University of Michigan Schools of Dentistry and Medicine and the Department of Pediatric Dentistry, School of Stomatology, University of Peking, China. P.P. was supported by the University of Michigan, School of Dentistry, Department of Orthodontics \& Pediatric Dentistry start-up funds. YY.W. is supported by the University of Peking. S.P. is supported by UM Department of Otolaryngology - Head and Neck Surgery. X.C wishes to thank Professors A.R Boccaccini and T.Kasuga for their support on the development and fabrication of the Ag-BG.

\section{Disclosure of potential conflict of interest}

The authors indicate no potential conflicts of interest.

\section{References}

Badylak S F (2002). The extracellular matrix as a scaffold for tissue reconstruction. Semin Cell Dev Biol 13: 377-383.

Badylak S F (2004). Xenogeneic extracellular matrix as a scaffold for tissue reconstruction.Transpl Immunol 12: $367-377$.

Badylak S F (2007). The extracellular matrix as a biologic scaffold material. Biomaterials 28: 3587-3593.

Balamurugan A, Balossier G, Laurent-Maquin D, Pina S, Rebelo AHS, Faure J, Ferreira JMF, (2008). An in vitro biological and anti-bacterial study on a sol-gel derived silver-incorporated bioglass system. Dent Mater 24: 13431351.

Blaker J, Gough J, Maquet V, Notingher I, Boccaccini A. (2003). In vitro evaluation of novel bioactive composites based on Bioglass ${ }^{\circledR}$-filled polylactide foams for bone tissue engineering scaffolds. J Biomed Mater Res A 67: 14011411.

Boruch AV, Nieponice A, Qureshi IR, Gilbert TW, Badylak SF. (2010). Constructive remodeling of biologic scaffolds is dependent on early exposure to physiologic bladder filling in a canine partial cystectomy model. J Surg Res 161: 217-225.

Burke FJ, Cheung SW, Mjör IA, Wilson NH. (1999). Reasons for the placement and replacement of restorations in vocational training practices. Prim Dent Care 6: 17-20.

Chatzistavrou X, Esteve D, Hatzistavrou E, Kontonasaki E, Paraskevopoulos KM, Boccaccini AR. (2010). Sol-gel based fabrication of novel glass-ceramics and composites for dental applications. Mater Sci Eng C 30: 730-739. 
Chatzistavrou X, Fenno JC, Faulk D, Badylak S, Kasuga T, Boccaccini AR, Papagerakis P. (2014). Fabrication and characterization of bioactive and antibacterial composites for dental applications. Acta Biomater 10: 3723-3732.

Chatzistavrou X, Kontonasaki E, Bakopoulou A, Theocharidou A, Sivropoulou A, Paraskevopoulos KM, Koidis P, Boccaccini AR, Kasuga T. (2012). Development of new sol-gel derived Ag-doped biomaterials for dental applications. MRS Online Proceed Lib 1417: doi. org/10.1557/opl.2012.743. [http://journals.cambridge.org/ action/displayAbstract?fromPage $=$ online $\&$ aid $=8542179 \&$ fileId=S1946427412007439]

Chatzistavrou X, Papagerakis S, Ma PX, Papagerakis P. (2012). Innovative approaches to regenerate enamel and dentin. Int J Dent 2012: 856470.

Chatzistavrou X, Paraskevopoulos KM, Salih V, Boccaccini AR, Kasuga T. (2012). Ag-doped sol-gel derived novel composite materials for dental applications. Key Eng Mater 493-494: 637-642.

Cheng L, Weir MD, Zhang K, Xu SM, Chen Q, Zhou X, Xu HH. (2012). Antibacterial nanocomposite with calcium phosphate and quaternary ammonium. J Dent Res 91: 460-466.

Currie LJ, Sharpe JR, Martin R. (2001). The use of fibrin glue in skin grafts and tissue-engineered skin replacements: a review. Plast Reconstr Surg 108: 17131726.

Cushing BL, Kolesnichenko VL, O’Connor CJ. (2004). Recent advances in the liquid-phase syntheses of inorganic nanoparticles. Chem Rev 104: 3893-3946.

Demarco FF, Casagrande L, Zhang Z, Dong Z, Tarquinio SB, Zeitlin BD, Shi S, Smith AJ, Nör JE. (2010). Effects of Morphogen and Scaffold Porogen on the Differentiation of Dental Pulp Stem Cells. J Endod 36: 1805-1811.

Forsback A-P, Areva S, Salonen JI. (2004). Mineralization of dentin induced by treatment with bioactive glass S53P4 in vitro. Acta Odontol Scand 62: 14-20.

Freytes DO, Badylak SF, Webster TJ, Geddes LA, Rundell AE. (2004). Biaxial strength of multilaminated extracellular matrix scaffolds. Biomaterials 25: 2353-2361.

Freytes DO, Martin J, Velankar SS, Lee AS, Badylak SF. (2008). Preparation and rheological characterization of a gel form of the porcine urinary bladder matrix. Biomaterials 29: 1630-1637.

Galler KM, Hartgerink JD, Cavender AC, Schmalz G, D'Souza RN. (2012). A Customized Self-Assembling Peptide Hydrogel for Dental Pulp Tissue Engineering. Tissue Eng Part A 18: 176-184.

Gronthos S, Mankani M, Brahim J, Robey PG, Shi S. (2000). Postnatal human dental pulp stem cells (DPSCs) in vitro and in vivo. Proc Natl Acad Sci U S A 97: 1362513630.

Hanks C, Fang D, Sun Z, Edwards C, Butler W. (1998). Dentin-specific proteins in MDPC-23 cell line. Eur J Oral Sci 106: 260-266.

Hench LL, Xynos ID, Polak JM. (2004). Bioactive glasses for in situ tissue regeneration. J Biomater Sci Polym Ed 15: 543-562.
Hong S-J, Yu H-S, Noh K-T, Oh S-A, Kim H-W. (2009). Novel scaffolds of collagen with bioactive nanofiller for the osteogenic stimulation of bone marrow stromal cells. J Biomater Appl 24: 733-750.

Hong Y, Huber A, Takanari K, Amoroso NJ, Hashizume R, Badylak SF, Wagner WR. (2011). Mechanical properties and in vivo behavior of a biodegradable synthetic polymer microfiber-extracellular matrix hydrogel biohybrid scaffold. Biomaterials 32: 3387-3394.

Imazato S, Ebi N, Takahashi Y, Kaneko T, Ebisu S, Russell RR. (2003). Antibacterial activity of bactericideimmobilized filler for resin-based restoratives. Biomaterials 24: 3605-3609.

Kellomaki M, Niiranen H, Puumanen K, Ashammakhi N, Waris T, Tormala P. (2000). Bioabsorbable scaffolds for guided bone regeneration and generation. Biomaterials 21: 2495-2505.

Kim J, Gu L, Breschi L, Tjäderhane L, Choi KK, Pashley DH, Tay FR. (2010). Implication of Ethanol Wetbonding in Hybrid Layer Remineralization. J Dent Res 89: 575-580.

Lansdown A (2002). Silver I: its antibacterial properties and mechanism of action. J Wound Care 11: 125-130.

Lansdown A. (2006). Silver in health care: antimicrobial effects and safety in use. Curr Probl Dermatol 33: 17-34.

Ljungh A, Moran AP, Wadstrom T. (1996). Interactions of bacterial adhesins with extracellular matrix and plasma proteins: pathogenic implications and therapeutic possibilities. FEMS Immunol Med Microbiol 16: 117-126.

Marelli B, Ghezzi CE, Barralet JE, Boccaccini AR, Nazhat SN. (2010). Three-dimensional mineralization of dense nanofibrillar collagen - bioglass hybrid scaffolds. Biomacromolecules 11: 1470-1479.

Mase VJ Jr, Hsu JR, Wolf SE, Wenke JC, Baer DG, Owens J, Badylak SF, Walters TJ. (2010). Clinical application of an acellular biologic scaffold for surgical repair of a large, traumatic quadriceps femoris muscle defect. Orthopedics 33: 511.

Maupomé G, Sheiham A. (1998). Criteria for restoration replacement and restoration life-span estimates in an educational environment. J Oral Rehabil 25: 896-901.

Mitsiadis TA, Papagerakis P. (2011). Regenerated teeth: the future of tooth replacement? Regen Med 6: 135-139.

Murdoch-Kinch CA, McLean ME. (2003). Minimally invasive dentistry. J Am Dent Assoc 134: 87-95.

Nam S, Won J-E, Kim C-H, Kim H-W. (2011). Odontogenic differentiation of human dental pulp stem cells stimulated by the calcium phosphate porous granules. J Tissue Eng: 812547.

Narayanan K, Srinivas R, Ramachandran A, Hao J, Quinn B, George A. (2001). Differentiation of embryonic mesenchymal cells to odontoblast-like cells by overexpression of dentin matrix protein 1. Proc Natl Acad Sci 98: 4516-4521.

Nieponice A, McGrath K, Qureshi I, Beckman EJ, Luketich JD, Gilbert TW, Badylak SF. (2009). An extracellular matrix scaffold for esophageal stricture prevention after circumferential EMR. Gastrointest Endosc 69: 289-296.

Oppermann RV, Rølla G, Johansen JR, Assev S. (1980). Thiol groups and reduced acidogenicity of dental plaque 
in the presence of metal ions in vivo. Scand J Dent Res 88: 389-396.

Patino MG, Neiders ME, Andreana S, Noble B, Cohen RE. (2002). Collagen as an implantable material in medicine and dentistry. J Oral Implantol 28: 220-225.

Pereira-Cenci T, Cenci MS, Fedorowicz Z, Marchesan MA. (2009). Antibacterial agents in composite restorations for the prevention of dental caries. Cochrane Database Syst Rev : CD007819. doi: 10.1002/14651858.CD007819.

Rahaman MN, Day DE, Sonny Bal B, Fu Q, Jung SB, Bonewald LF, Tomsia AP. (2011). Bioactive glass in tissue engineering. Acta Biomater 7: 2355-2373.

Rezwan K, Chen QZ, Blaker JJ, Boccaccini AR. (2006). Biodegradable and bioactive porous polymer/ inorganic composite scaffolds for bone tissue engineering. Biomaterials 27: 3413-3431.

Ringe J, Kaps C, Burmester GR, Sittinger M. (2002). Stem cells for regenerative medicine: advances in the engineering of tissues and organs. Naturwissenschaften 89: $338-351$.

Russell A, Path F, Sl FP, Hugo W. (1994). 7 Antimicrobial activity and action of. Progr Med Chem 31: 351-370.

Sachlos E, Reis N, Ainsley C, Derby B, Czernuszka J. (2003). Novel collagen scaffolds with predefined internal morphology made by solid freeform fabrication. Biomaterials 24: 1487-1497.

Sakai V, Cordeiro M, Dong Z, Zhang Z, Zeitlin B, Nör J. (2011). Tooth slice/scaffold model of dental pulp tissue engineering. Adv Dent Res 23: 325-332.

Saravanapavan P, Gough JE, Jones JR, Hench LL. (2004). Antimicrobial macroporous gel-glasses: dissolution and cytotoxicity. Key Eng. Mater. 254-256: 1087-1090.

Sauro S, Osorio R, Osorio E, Watson TF, Toledano M. (2013). Novel light-curable materials containing experimental bioactive micro-fillers remineralise mineraldepleted bonded-dentine interfaces. J Biomater Sci Polym Ed 24: 940-956.

Singelyn JM, Sundaramurthy P, Johnson TD, SchupMagoffin PJ, Hu DP, Faulk DM, Wang J, Mayle KM, Bartels K, Salvatore M, Kinsey AM, Demaria AN, Dib
N, Christman KL. (2012). Catheter-deliverable hydrogel derived from decellularized ventricular extracellular matrix increases endogenous cardiomyocytes and preserves cardiac function post-myocardial infarction. J Am Coll Cardiol. 59: 751-763.

Turner NJ, Yates AJ, Jr., Weber DJ, Qureshi IR, Stolz DB, Gilbert TW, Badylak SF. (2010). Xenogeneic extracellular matrix as an inductive scaffold for regeneration of a functioning musculotendinous junction. Tissue Eng Part A 16: 3309-3317.

Valentin JE, Turner NJ, Gilbert TW, Badylak SF. (2010). Functional skeletal muscle formation with a biologic scaffold. Biomaterials 31: 7475-7484.

Wang J, Liu X, Jin X, Ma H, Hu J, Ni L, Ma PX. (2010). The odontogenic differentiation of human dental pulp stem cells on nanofibrous poly(l-lactic acid) scaffolds in vitro and in vivo. Acta Biomater 6: 3856-3863.

Wu M, Suryanarayanan K, van Ooij W, Oerther D. (2007). Using microbial genomics to evaluate the effectiveness of silver to prevent biofilm formation. Water Sci Technol 55: 413-419.

Xynos I, Hukkanen M, Batten J, Buttery L, Hench L, Polak J. (2000). Bioglass ${ }^{\circledR} 45$ S5 stimulates osteoblast turnover and enhances bone formation in vitro: implications and applications for bone tissue engineering. Calcif Tissue Int 67: 321-329.

Yoshida K, Atsuta M. (1999). Properties of fluoridereleasing light-activated resin cement. Dent Mater 15: 337-341.

Zhang K, Melo MA, Cheng L, Weir MD, Bai Y, Xu HH. (2012). Effect of quaternary ammonium and silver nanoparticle-containing adhesives on dentin bond strength and dental plaque microcosm biofilms. Dent Mater 28: 842-852.

\section{Editor's Note:}

All questions/comments by the reviewers were answered by text changes. There is hence no Discussion with Reviewers section. 